\title{
Pilot-scale study on masking agents for titanium tanning
}

\author{
Monica Puccini ${ }^{1, a}$, Maurizia Seggiani ${ }^{1, b}$, Christian Pomelli ${ }^{2, c}$, Sandra Vitolo ${ }^{1, d}$ \\ ${ }^{1}$ Department of Civil and Industrial Engineering, University of Pisa, Largo Lucio Lazzarino 1, 56126 \\ Pisa, Italy \\ ${ }^{2}$ Department of Pharmacy, University di Pisa, Via Bonanno Pisano 6, 56126 Pisa, Italy \\ ${ }^{a}$ monica.puccini@unipi.it, ${ }^{b}$ maurizia.seggiani@unipi.it, \\ cchristian.pomelli@farm.unipi.it, 'sandra.vitolo@unipi.it
}

Keywords: tanning process, titanyl sulfate, masking agent, tannage

\begin{abstract}
The many advantages offered by chrome tanning justify its widespread use for production of almost all types of leather. However, the traditional chromium(III) tanning process is constantly under threat from the pressure of legislation, and ever-tightening restrictions require to minimize chromium-containing effluents discharge and chromium-containing wastes production. Recently, the manufacture and use of chromium(III) free tanning agents compounds have been studied intensively. Among these, Titanium (IV)-based salts is one of the most promising substitutes.

In this study, the use of titanyl sulfate as tanning agent for the production of high-quality bovine upper leather was investigated. In order to optimize the titanium tanning performances, a comparative evaluation, on pilot-scale, of citrate and lactate ions as masking agents was performed. The developed process has been validated through various analyses of the obtained crust leathers such as shrinkage temperature, scanning electron microscopy, and physical testing. The final leather obtained with the innovative method shows similar properties to those of the conventional tanned leather in terms of technical and mechanical properties.
\end{abstract}

\section{Introduction}

The emerging Health, Safety and Environment regulations, as well as the restrictions adopted in some countries to the use of chromium-tanned leather for certain purposes, have attracted a worldwide interest in the development of novel tanning processes [1-9].

Among the alternative mineral tanning agents investigated for replacing chromium, Titanium (IV)based salts have received a specific attention over the past century [10].

The hydrolysis and coordination polymerization ability of Ti(IV) enables it to easily form large-size coordination polymers, even colloid particles and eventual precipitate. Traditional Ti(IV) tanning is carried out only at rather low $\mathrm{pH}$, where $\mathrm{Ti}(\mathrm{IV})$ does not precipitate but it cannot coordinate well with collagen, thus giving only moderate tanning power. The use of specific masking agents (organic ligands) may lead to improved stability of the titanium sulfate solutions at relatively higher $\mathrm{pH}$, where titanium can better coordinate with collagen to form stable crosslinks rather than a gross physical deposit in the hide. Among the potential candidates as masking agents, hydroxylcarboxylic acids (lactic, tartaric, citric, sulfosalycilic, malic, ascorbic) have proved to be promising because of their effectiveness of increasing the aging and alkali stability of the titanium solutions through formation of stable chelate-type coordination compounds with $\mathrm{Ti}^{4+}$. Moreover, this compounds are easily obtained, inexpensive, nontoxic and colorless or light-colored [11].

As far as bovine upper leather is concerned, even if titanium tanning is considered one of the most promising substitutes of chrome tanning, it is a fact that, at present, titanium tanning industrial applications are very limited because the chrome tanned leather still remain unmatchable for its hydrothermal stability and excellent technical properties. 
A previous work [11], in which the effect of citrate as masking agent has been investigated on pilot scale to assess the feasibility of the industrial use of titanium sulfate in the manufacture of high-quality bovine upper leathers, has revealed the necessity of additional investigation of process conditions and alternative masking agents to further optimize the titanium tanning performances.

In this work, a comparative evaluation, on pilot-scale, of citrate and lactate ions as masking agents to assess the optimal masking procedure was reported. The titanium-based tanning recipe has been developed for the production of bovine upper leather. The developed process has been validated through various analyses of the obtained crust leathers, such as shrinkage temperature, scanning electron microscopy, and physical testing.

\section{Experimental procedures}

Materials. Titanyl sulfate ( $\mathrm{TiOSO}_{4} \cdot \mathrm{xH}_{2} \mathrm{O}, \mathrm{CAS}$ No. 13825-74-6) was supplied by Sigma Aldrich in powder form. All other chemicals used for leather processing were commercial grade and purchased from local suppliers.

Fleshed veal hides (weight class14-18 kg) were provided by a tannery of the Santa Croce sull'Arno (Tuscany, Italy) leather district after the traditional soaking/liming/unhairing treatments.

Preparation of tanned (Deliming/Bating/Pickling and Tanning), and crust leather (retanning, dyeing, fatliquoring). The hides were delimed and bated in a pilot-scale polypropylene drum (1 m diameter and $0.5 \mathrm{~m}$ length, each batch loaded with two veal hides), according to a recipe usually applied to prepare hides for the standard chrome tanning. The dosage of deliming agent (ammonium sulfate) was adjusted in order to obtain a complete elimination of lime in the whole section of the hides and, consequently, to get a higher openness of the fibers that facilitates the penetration of the tanning agents. After that, the hides were pickled and tanned, in the same pilot drum, according to the procedure and recipe reported in a previous work [11]. The dosage of the masking agent is dependent upon the $\mathrm{pH}$ value that is intended to be achieved at the end of the tanning process. In this work, an end-tanning $\mathrm{pH}$ of 3.2 was selected according to the results of preliminary screening runs on laboratory scale. According to the end-tanning $\mathrm{pH}$ selected, the dosage of citric and lactic acid, enough to guarantee titanium stability in solution [10], was $1.5 \%$ and $1.65 \%$ (wt $\%$ based on fleshed hide weight).

After tanning, the hides were pressed and shaved. Afterwards, retanning, dyeing, and fatliquoring treatments were carried out on the shaved leathers to obtain high-quality crust bovine upper leather. Physical testing and visual assessment of the crust leather. The shrinkage temperature was determined according to the IULTCS official testing method IUP16 using a shrinkage tester.

The leather samples for physical testing were cut from the crust leathers according to the official sampling position (IUP 2000). The physical properties were evaluated in accordance with the Italian standard procedures (UNI 10594) for upper leather. The load at tear was determined according to the UNI EN ISO 3377-1 method using an electronic dynamometer (Pegasil, Mod. Marte) which also gives the extension at tear as a secondary output. The extension and load at grain crack were determined according to the UNI EN ISO 3379 (recently converted in UNI 11308) method using a lastometer (Pegasil, Mod. EL-51E).

Experienced technologists of Po.Te.Co. assessed the organoleptic properties of the crust and finished leathers by hand and visual examination.

Titanium distribution across the section of the tanned leathers was analyzed by scanning electron microscopy (SEM) coupled with energy x-ray dispersion (EDS) by using a JEOL 5600 LV electron scanning microscope. 


\section{Results and discussion}

No precipitation of titanium complexes was observed in the citrate-masked tanning float, while a slight clouding of the lactate-masked tanning float was evidenced.

The properties of the obtained crust leathers are reported in Table1. The data reported are mean values of at least three determinations. As it can be seen, the physical properties of lactate-masked crust leathers comply with the standard required for high-quality bovine upper leather.

\begin{tabular}{|l|c|c|c|}
\hline & Citrate-masked & Lactate-masked & $\begin{array}{c}\text { UNI 10594 } \\
\text { guidelines }\end{array}$ \\
\hline Physical properties & & & \\
Thickness (mm) & 1.35 & 1.30 & \\
Shrinkage temperature $\left(\mathrm{T}_{\mathrm{g}}\right)\left({ }^{\circ} \mathrm{C}\right)$ & 77 & 85 & $30-80^{1}$ \\
Tearing load $(\mathrm{N})$ & 27.6 & 31.1 & $150-200$ \\
Tear strength (N/mm) & 20.4 & 24.0 & $\geq 7$ \\
Load at grain crack $(\mathrm{N})$ & 178.1 & 202.4 & \\
Distention at grain crack $(\mathrm{mm})$ & 8.72 & 9.67 & \\
& & & \\
Organoleptic properties & & \\
Softness & 3 & 4 & \\
Fullness & 2 & 3 & \\
Roundness & 2 & 4 & \\
Grain blowing & 2 & 6 & \\
Dyeability & 6 & 4 & \\
Hand & 3 & & \\
\hline
\end{tabular}

1 Depending on the end use.

2 Reference: rating 5 assigned to a standard chromium tanned crust leather

Table 1. Physical and organoleptic properties of the titanium-tanned crust leathers.

A comparative evaluation of the physical properties of citrate and lactate-masked crust leathers, obtained according to the same recipe and procedures, shows a better performance of lactate as masking agent. The lactate-masked crust leathers showed a higher shrinkage temperature as well as a higher strength to mechanical loads coupled with a global much better performance in terms of organoleptic properties. Assuming a reference rating 5 for the technical properties of a standard Crtanned leathers, lactate-masked Ti-tanned leathers technical properties appear much similar to conventionally tanned ones and a greater affinity to anionic dyestuffs (dyeability).

The SEM images of the cross section of masked Ti-tanned leathers along with the Titanium distribution are shown in Figg. 1 and 2. A better compactness of the fibril bundles as well as a more uniform distribution of Titanium along the section, observed for the lactate-masked leathers, explain their better physical and technical performance displayed. 

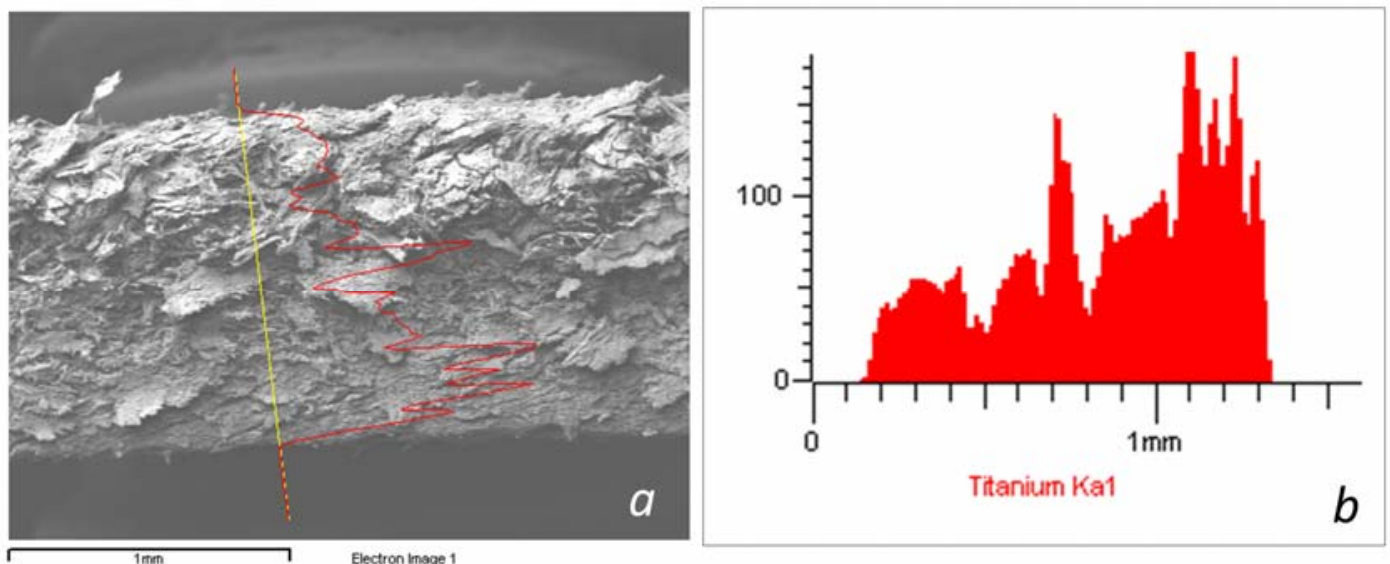

Fig. 1. SEM picture of the cross section of the citrate-masked crust leather (a), and Titanium distribution (b)
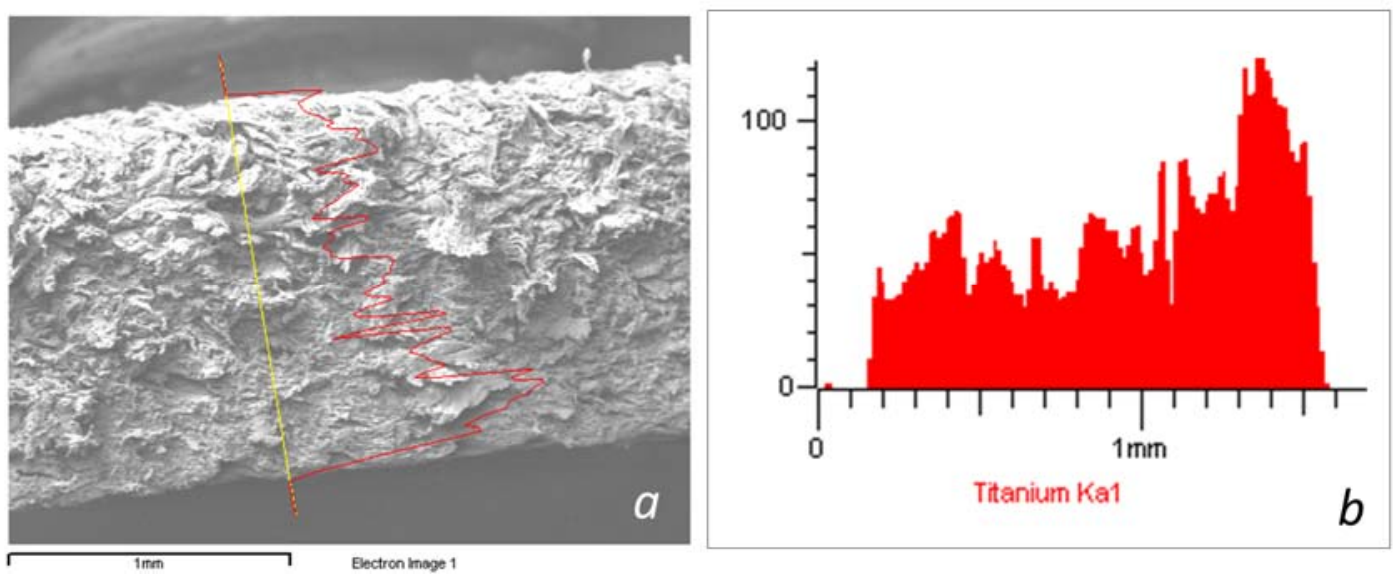

Fig. 2. SEM picture of the cross section of the lactate-masked crust leather (a), and Titanium distribution (b)

\section{Conclusions}

In the development of a Ti-tanning process capable to compete with the standard Cr-tanning procedure, a comparative evaluation of citrate and lactate effectiveness as masking agent has been performed on pilot-scale.

The use of lactate promotes a more effective tanning action of Titanium, allowing the formation of more stable coordination complexes between the tanning agent and the collagen carboxylic groups. This action produces a better compactness of the fibril bundles as well as a more uniform distribution of Titanium along the section and, consequently, better physical and technical performances. 


\section{References}

[1] S. Vitolo, M. Seggiani, A. D’Aquino, N. Barbani, B. Naviglio, M. Tomaselli: J. Am. Leather Chem. As. Vol. 98 (2003), p. 123

[2] A.D. Covington, in: Tanning Chemistry, edited by RSC Publishing, Cambridge, UK (2011)

[3] A. D'Aquino, G. D'Elia, B. Naviglio, M. Seggiani, M. Tomaselli, S. Vitolo: J. Soc. Leath. Tech. Ch. Vol. 87 (2003), p. 189

[4] M. Puccini, D. Castiello: Adv. Mater. Res. 933 (2014), p. 144

[5] A. D’Aquino, G. D’Elia, M. Seggiani, S. Vitolo, B. Naviglio, M. Tomaselli: J. Am. Leather Chem. As. Vol. 99 (2004), p. 26

[6] A.E. Musa, G.A. Gasmelseed: J. Soc. Leath. Tech. Ch. Vol. 96 (2012), p. 239

[7] M. Puccini, M. Seggiani, D. Castiello, S. Vitolo: Chem. Eng. Trans. 36 (2014), p. 193

[8] A. D’Aquino, N. Barbani, G. D’Elia, D. Lupinacci, B. Naviglio, M. Seggiani, M. Tomaselli, S. Vitolo: J. Soc. Leath. Tech. Ch. Vol. 88 (2004), p. 47

[9] M. Puccini, M. Seggiani, D. Castiello, S. Vitolo: J. Am. Leather Chem. As. Vol. 109 (2014), p. 110

[10] B. Peng, B.I. Shi, K. Ding, H. Fan, D.C. Shelly: J. Am. Leather Chem. As. Vol. 102 (2007), p. 297

[11] M. Seggiani, M. Puccini, S. vitolo, C. Chiappe, C.S. Polmelli, D. Castiello: Clean Tech. Environ. Policy (2014), in press 